\title{
A NEW SYSTEM FOR MEASURING THE DEFLECTION OF THE BEAM WITH THE SUPPORT OF DIGITAL HOLOGRAPHIC INTERFEROMETRY
}

\author{
Jozef Černecký $^{*}$ - Pavol Božek ${ }^{* *}$ - Elena Pivarčiová ${ }^{*}$
}

\begin{abstract}
The contribution deals with the comparison of possibilities of utilizing two experimental methods: digital and classical holographic interferometry for the visualization of beam motion. The girders are used in civil and mechanical engineering and considering the technical point of view it is necessary to learn to what extent the beam is deformed at the load and how much it can withstand.

K e y w o r d s: holographic interferometry, digital holographic interferometry, beam
\end{abstract}

\section{INTRODUCTION}

Due to the external forces activity the solids change their shape - they deform. The deformations can be flexible (temporary), by which the solid regains its original shape after the force activity is finished, and inflexible, by which the solid does not regain its original shape and the force activity consequences are of permanent character.

The solid is characterized by the fact that under common conditions it keeps its solidity. This solidity can be impaired by the activity of sufficiently strong forces. After exceeding a specific critical force the solid cannot withstand the load and is distorted (broken, torn, etc).

Five simple deformations are distinguished: deformation by tension, compression, bending, shear and torsion. In technical practice we can encounter mainly the deformations comprising several types of simple deformations.

The beam is the bearing part of the specific technical piece of work determined for the forces transfer. It is usually a static transfer of the other solids forces activity. The beam is frequent in civil engineering and in the architecture of large buildings as well as it can be found in mechanical engineering in heavy machinery. From the technical point of view it is important to know how the beam is deformed under the load and how much it can withstand.

\section{THEORETICAL PART}

Holographic interferometry is an optical display method which allows obtaining the information in the form of an observable image. The holographic interferometry compares two information waves originally not existing at the same time.
The method of two expositions is based on the interference of two reconstructed waves related to two different states of the object - before and after the deformation while two holograms are recorded on one holographic plate. After illuminating the hologram via the reference wave, both the waves - insignificantly different - are reconstructed. Their interference after the transfer through the optical system results in the set of interference stripes on the shade (Fig. 1(b)).

Interferogram carries the information on the phase change between the waves; however, the interference phase cannot be unambiguously extracted from one interferogram. The interference phase is usually calculated from three or more phase shifted interferograms via the phase shift algorithm which requires complementary experimental effort.

Digital holography requires a different way of processing. The authors aimed at obtaining the record of "real" holograms via the electronic device and executing the process of computer-aided optical reconstruction.

In each state of the object one digital hologram is recorded. Instead of overlapping these holograms as it is common with the classical holographic interferometry, and using the photographic plates, the digital holograms are reconstructed separately. From the result complex amplitudes the phases are calculated (Schnars, Jueptner, 2005)

$$
\begin{aligned}
& \varphi_{1}(\xi, \eta)=\arctan \frac{\operatorname{Im} \Gamma_{1}(\xi, \eta)}{\operatorname{Re} \Gamma_{1}(\xi, \eta)}, \\
& \varphi_{2}(\xi, \eta)=\arctan \frac{\operatorname{Im} \Gamma_{2}(\xi, \eta)}{\operatorname{Re} \Gamma_{2}(\xi, \eta)} .
\end{aligned}
$$

Index 1 assigns State 1, index 2 assigns State 2. In the equations (1) and (2) the phase achieves the values be-

\footnotetext{
* Technical University in Zvolen, Faculty of Environmental and Manufacturing Technology, jozef.cernecky@tuzvo.sk, elena.pivarciova @tuzvo.sk ${ }^{* *}$ The Faculty of Materials Science and Technology, Slovak University of Technology (Institute of Applied Informatics, Automation and Mathematics), Trnava, Slovakia, pavol.bozek@stuba.sk
} 


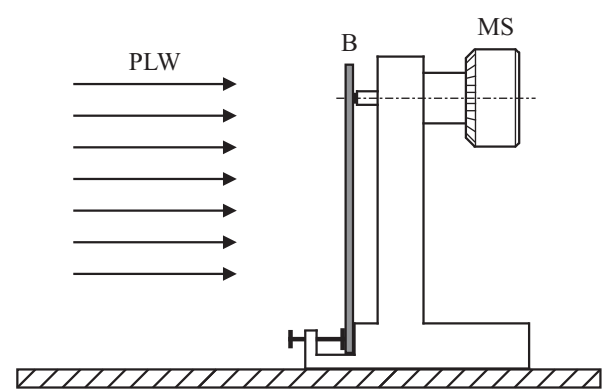

(a)

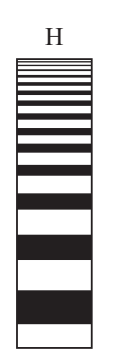

(b)

Fig. 1. Normal deformation of the firmly fixed beam with interference fringes observed on the beam front side of PLW - planar light wave, B - beam, MS - micrometric screw, $\mathrm{H}$ - hologram with interference fringes

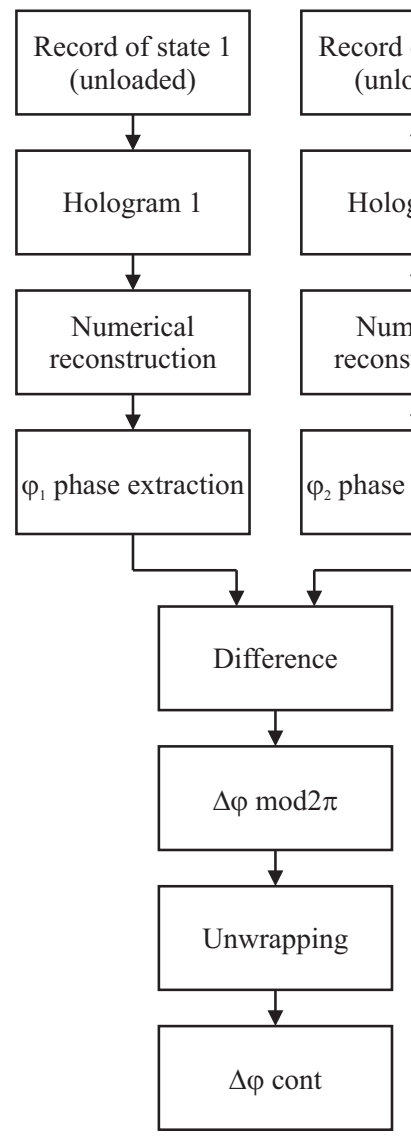

(a)

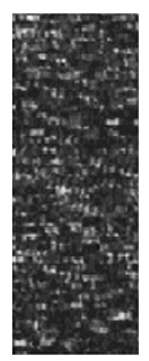

(b)

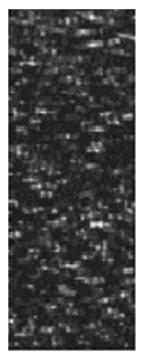

(c)

Fig. 2. Process of digital holographic interferometry (Schnars, Jueptner, 2005) (a) - Algorithm of digital holographic interferometry, (b) - Digital hologram of beam before bending, (c) - Digital hologram of beam after bending

tween $-\pi$ and $\pi$, the main values of the function of arctangents. The interference phase is calculated directly by subtraction (Schnars, Jueptner, 2005)

$$
\Delta \varphi= \begin{cases}\varphi_{1}-\varphi_{2} & \text { if } \varphi_{1} \geq \varphi_{2} \\ \varphi_{1}-\varphi_{2}+2 \pi & \text { if } \varphi_{1} \geq \varphi_{2}\end{cases}
$$

The equation allows calculating the module of $2 \pi$ interference phase directly from the digital holograms. The

generation as well as the evaluation of the interferogram is not necessary. The algorithm of the digital holographic interferometry is shown in Fig. 2(a).

The subject of research was represented by the console beam with firmly anchored end. The beam was subjected to bending due to the micrometric screw operating on the unfixed end (Fig. 1(a)). Figs. 2(b), (c) show two digital holograms recorded in different states. Between two recordings the beam was subjected to the micrometric screw. Each hologram was separately reconstructed via Fresnel transformation. According to the equation (3) the result of the phases difference is represented by the interference phase Fig. 3(b).

Digital holographic interferometry has the following properties

- it does not require wet chemical or other processing of holograms,

- from one digital hologram various object can be reconstructed via numerical methods,

- it utilizes the display without lenses, ie no deviations due to the drawing devices.

The phase differences can be calculated directly from the holograms without producing and processing the interferogram. This interesting property is possible only within the digital holographic interferometry; conventional holographic interferometry needs the phase shift of interferograms (or other complementary information) to find out about the phase.

\section{EXPERIMENTAL PART}

The tested beam was illuminated by the planar wave perpendicular to its surface. Laser radiation diffused on the beam was recorded on the hologram. Subsequently, due to the micrometric screw activity of the free end of the beam was slightly shifted and the second exposition was recorded.

Figure 1(a) shows the scheme illustrating the deformation of the firmly fixed beam with dimensions of $4 \times 1 \times 0.5 \mathrm{~cm}$ on which the interference fringes on the front side of the console beam are observable. Figure 3 shows the holographic interferograms obtained via the method of two expositions and digital holography.

Due to the micrometric screw activity the shift occurs and the individual points are replaced to the position described by the function (Vest, 1997)

$$
f=Z(x)
$$

Before the deformation the light wave moves the distance of 10 from the source to the point of the object and back to the observer (or camera) and after the object deformation it moves the following distance

$$
L_{0}-2 Z(x)
$$




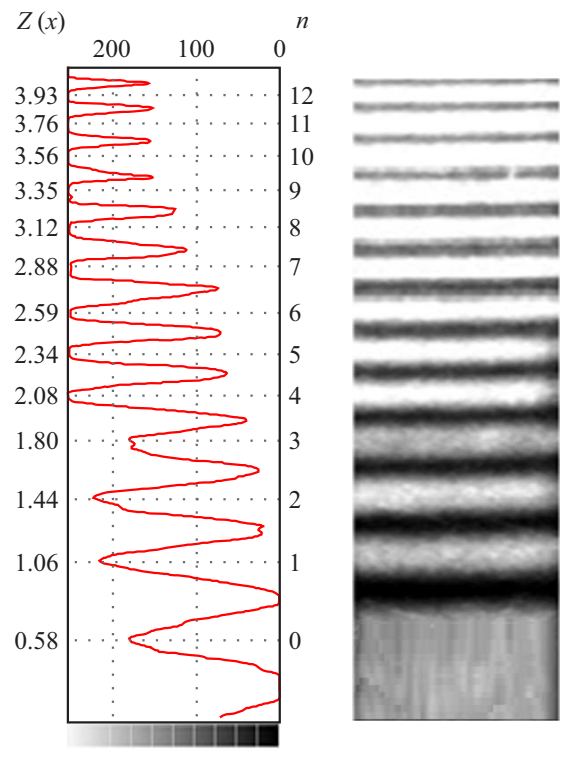

(a)

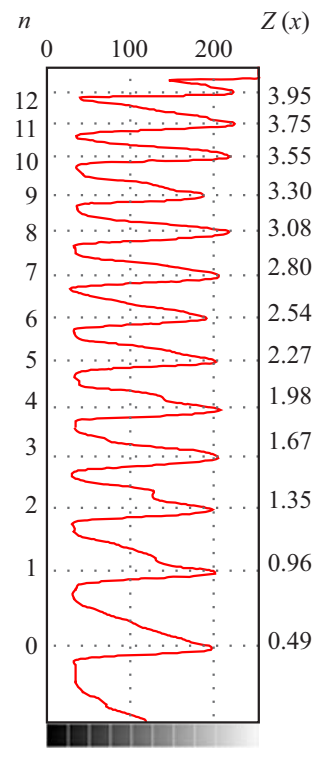

(b)

Fig. 3. Holographic interferograms of beam (a) - Interferogram of console beam bending, obtained via two expositions method, (b) Interferogram of console beam bending obtained via digital holography

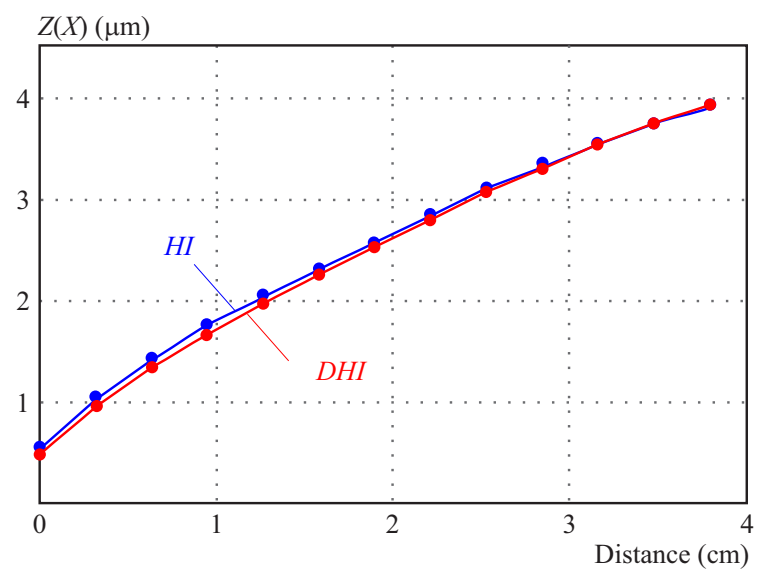

Fig. 4. Deformation of bent beam

Table 1. Evaluation of holographic interferograms

\begin{tabular}{cccc}
\hline$n$ & $\begin{array}{c}Z(X) \\
(\mu \mathrm{m})\end{array}$ & $\begin{array}{c}H I \\
(\mathrm{~cm})\end{array}$ & $\begin{array}{c}D H I \\
(\mathrm{~cm})\end{array}$ \\
\hline 0 & 0.00 & 0.58 & 0.49 \\
1 & 0.32 & 1.06 & 0.96 \\
2 & 0.63 & 1.44 & 1.35 \\
3 & 0.95 & 1.80 & 1.67 \\
4 & 1.26 & 2.08 & 1.98 \\
5 & 1.58 & 2.34 & 2.27 \\
6 & 1.90 & 2.59 & 2.54 \\
7 & 2.21 & 2.88 & 2.80 \\
8 & 2.53 & 3.12 & 3.08 \\
\hline
\end{tabular}

The corresponding phase change equals (Vest, 1997)

$$
\Delta \Phi(x)=(2 \pi / \lambda)[2 Z(x)],
$$

where $\lambda$ is the wave length of laser radiation.

The light fringes on the interferogram are assigned the interference order. As the basis of the beam is not shifted, the light fringe is assigned $n=0$. The next light fringes are assigned as follows $n=1,2,3, \ldots$ the fringe numbered as $n$ corresponds to the phase change (6).

After the modification we obtain the relation for the calculation of the shift in the point given

$$
Z(x)=n \lambda / 2 .
$$

\section{ACHIEVED RESULTS}

Figure 4 shows the analysis of the holographic interferograms, this as well as Table 1 displays the evaluation of holographic interferograms from Fig. 3 according to the relation (7).

As show in Fig. 4, the shift of the end of the fixed beam correlates well with the analysed interferograms. In the experiment the micrometric screw was used as using it we were able to set the shift in the upper beam part accurately.

\section{CONCLUSION}

The experimental subject matter represents the issue which can be dealt with only experimentally. In order to be able to find the solution to the subject related, we carry out experiments. The contribution focuses on the comparison of utilizing two experimental methods used in the experimental mechanics: the classical holographic interferometry and digital holographic interferometry. The classical holographic interferometry is the method by which it is possible to record two states of the solid: before and after deformation. Three dimensional objects of random shape without any surface coating can be observed. It is the so called "wet" method when the hologram needs 
to be processed via photochemical way. This drawback is eliminated by the digital holographic interferometry by which we are able to record two states of the solid via the so called "dry" way - ie electronically which substantially accelerates the process of the observed solids interferogram.

Regarding the results quality, so far the images are of higher quality than by the classical holographic interferometry when compared to the images obtained via the digital holographic interferometry. This is caused by the quality and resolution capability of CCD sensors of the cameras used.

The quality also depends on the evaluation software. For the analysis of the image of the digitally obtained interferogram we used the evaluation software commonly utilized in the classical holographic interferometry.

\section{REFERENCES}

[1] ČERneCKÝ, J.-PIVARČIOVÁ, E.: Possibilities and Prospects of Holography, Izhevsk State Technical University, Russia, 2007.

[2] VEST, CH. M.: Holographic Interferometry, Wiley Inc., New York, 1979.

[3] SYROVA, L.-RAVAS, R.-GRMAN, J.: Principles and Application of Visualization Methods, Journal of Electrical Engineering No. 9-10 (2001).

[4] SCHNARS, U.-JUEPTNER, W.: Digital Holography, Springer Verlag, Berlin, 2005.

[5] BOŽEK, P.-TURYGIN, Y.: Measurement of the Operating Parameters and Numerical Analysis of the Mechanical Subsystem, Measurement Science Review 14 No. 4 (2014), 198-203.

[6] SZYMAŃSKI, T.-WOŚKO, M.-PASZKIEWICZ, B.-INDYKIEWICZ, K.-PASZKIEWICZ, R.: Correlation of Selected Problems during GaN movpe Epitaxy on Si Substrates with In-Situ Interferometer Observation, Journal of Electrical Engineering yr2014 No. 5.

[7] PUDiŠ, D.- ̌̌KRINIAROVA, J.-MARTINČK, I.-KOVÁČ, J.-TARJANYI, N.-HAŠČÍK, Š.: Periodic Structures Patterned on Metal And III-V Compound Surfaces Using Two-beam
Interference Method, Journal of Electrical Engineering 60 No. 3 (2009), 166-169

Received 2 August 2014

Jozef Černecký born in 1959 in Zvolen, Slovakia. Graduated from Military academy in Brno, specialization tank and automobile in 1984. He received the Candidate of Science degree $(\mathrm{PhD})$, in 1992 from the Technical University in Zvolen, Faculty of Wood Technology and achieved the Associate Professor title at Technical University in Zvolen in the branch of Engineering of Machines and Equipment. He presently holds the position of Associate Professor at the Department of Environmental and Forestry Machinery of Technical University in Zvolen. He published 7 scientific monographs and 150 papers in national and international publications. Fields of research: holography, heat transfer, air protection.

Pavol Božek born in 1954 in Trnava, Slovakia. Graduated from Slovak University of Technology Bratislava, Slovakia in 1972 receiving diploma in engineering, later Candidate of Science (PhD), and Associate Professor at Institute of Applied Informatics, Automation and Mathematics. At present he holds position of Associate Professor at the Faculty of Materials Science and Technology of Slovak University of Technology (Institute of Applied Informatics, Automation and Mathematics), Trnava, Slovakia. Over 257 scientific publications in international journals and conference proceedings. Fields of research: robotics, mechatronics.

Elena Pivarčiová born in 1967 in Nitra, Slovakia. Graduated from Pedagogic Faculty in Nitra, in mathematics, biology and computer sciences in 1991. She finished PhD studies in 2002 at Faculty of Wood Sciences and Technology of Technical University in Zvolen. She achieved the Associate Professor title at Czech Technical University in Prague in 2013. Presently holds position of Associate Professor at the Department of Machinery Control and Automation Technology of Technical University in Zvolen. She published 3 scientific monographs and 100 papers in national and international publications. Fields of research: programming, holography, biometrics and fingerprint verification, image processing, signal processing. 